\title{
Interest Rate Rules for Fixed Exchange Rate Regimes*
}

\author{
Gianluca Benigno \\ London School of Economics \\ Pierpaolo Benigno \\ New York University \\ Fabio Ghironi ${ }^{\dagger}$ \\ Boston College
}

First draft: March 9, 2000

This draft: October 13, 2003

Comments welcome

\begin{abstract}
This paper shows that properly designed interest rate rules can be consistent with maintaining exchange rate stability. It sheds light on the relation between interest rate rules, exchange-rate regimes, and determinacy of the rational expectation equilibrium in a modern macroeconomic framework.
\end{abstract}

Keywords: Fixed exchange rates; Interest rate rules

JEL Classification: F31; F33; F41

\section{Introduction}

The performance of alternative rules for interest rate setting by central banks of open economies has been the subject of increasing attention in the literature. ${ }^{1}$ Interest rate rules can be used to achieve a variety of policy goals. Among these, properly designed interest rate rules can be consistent with maintaining exchange rate stability.

\footnotetext{
${ }^{*}$ We thank Leonardo Bartolini, Charles Carlstrom, Peter Ireland, Maurice Obstfeld, Paolo Pesenti, and Giorgio Primiceri for comments and useful conversations. Remaining errors are ours.

${ }^{\dagger}$ G. Benigno: Department of Economics, London School of Economics, Houghton Street, London WC2A 2AE, United Kingdom; g.benigno@lse.ac.uk. P. Benigno: Department of Economics, New York University, 269 Mercer Street, New York, NY 10003, U.S.A.; pierpaolo.benigno@nyu.edu. F. Ghironi: Department of Economics, Boston College, 140 Commonwealth Avenue, Chestnut Hill, MA 02467-3859, U.S.A.; fabio.ghironi@bc.edu.

${ }^{1}$ Several contributions are collected in the web page on "Monetary Policy Rules in Open Economies," http://www.geocities.com/monetaryrules/mpoe.htm.
} 
This paper sheds light on the relation between interest rate rules, exchangerate regimes, and determinacy of the rational expectation equilibrium of the economy in a modern macroeconomic framework.

First, we show that, although a fixed exchange rate implies equality between the domestic and foreign interest rates, pegging the domestic interest rate to the foreign one is not sufficient to fix the exchange rate in all periods. Indeed, simple interest rate pegging by the follower country in the exchange-rate arrangement results in indeterminacy of the exchange rate and of the real economy.

We propose alternative interest rules for the follower country that determine a unique equilibrium with a fixed exchange rate. The rules we consider produce equality between the domestic and foreign interest rate endogenously in all periods as a feature of the rational expectations equilibrium. We show that there is a multiplicity of rules consistent with a fixed exchange rate regime. Because all these rules reduce endogenously to equality of domestic and foreign interest rates, they produce identical levels of welfare in a determinate economy. Multiple equilibria can arise only when the commitment to the rule that yields exchange rate stability and determinacy is not perfectly credible.

Determinacy of the fixed exchange rate does not necessarily imply determinacy of other domestic (or foreign) variables. Assuming that also the leader country is following an interest rule, for the world economy to be determinate, it is necessary that the interest setting rules of both countries be consistent with determinacy. ${ }^{2}$ The rule followed by the leader country determines the nature of the fixed exchange rate regime because it sets the course of monetary policy for the world economy. In this sense, there is a multiplicity of (fixed exchange rate) regimes: changes in the rule of the leader country face the follower with a change in the global monetary environment. In turn, this changes the welfare level implied by sticking to the fixed exchange rate commitment, although the rule through which the commitment is implemented by the follower is welfareneutral.

The structure of the paper is as follows. Section 2 shows that interest rate pegging does not yield a fixed exchange rate and generates indeterminacy, holding the monetary rule of the leader country exogenous. Section 3 shows how to design interest rate rules that are consistent with a fixed exchange rate commitment. Section 4 discusses the importance of the rule followed by the leader country for determinacy of the world equilibrium and the nature of the global monetary regime. Section 5 concludes.

\section{The Mirage of Fixing the Exchange Rate through Interest Rate Pegging}

We assume that the world economy consists of two countries: home and foreign. We keep the formal apparatus at a minimum and do not present a full-fledged

\footnotetext{
${ }^{2}$ Woodford (2003, Ch. 2) discusses the importance of ensuring equilibrium determinacy in monetary models. See also Carlstrom and Fuerst (2001).
} 
microfounded model of the two economies. Initially, we hold the leader's policy rule (if any) as given and focus on the follower country. We only restrict the foreign country's policymaking to be consistent with a "leadership" position in a fixed exchange rate regime by assuming that the foreign country never targets a level of the exchange rate that differs from that chosen by home.

Agents in this country maximize a utility function that depends on consumption and, possibly, other arguments, such as leisure or money balances. We assume that the period utility function is additively separable in the various arguments and well-behaved in each of them. ${ }^{3}$ Among the financial assets that agents can hold, there are bonds denominated in units of the domestic currency and bonds denominated in units of the foreign currency. The time $t$ interest rate on home (foreign) currency bonds is $i_{t}\left(i_{t}^{*}\right)$. Agents receive interest payments at time $t+1$. We denote consumption with $C$, the Consumer Price Index (CPI) with $P$, and the agents' discount factor with $\beta$. $E_{t}$ is the rational expectation operator, conditional on information available at time $t$.

The Euler equation for holdings of domestic bonds is:

$$
\beta\left(1+i_{t}\right) E_{t}\left(\frac{U^{\prime}\left(C_{t+1}\right)}{P_{t+1}}\right)=\frac{U^{\prime}\left(C_{t}\right)}{P_{t}} .
$$

Letting $S$ denote the exchange rate (in units of the domestic currency per unit of the foreign one), holdings of foreign currency bonds are determined by:

$$
\beta\left(1+i_{t}^{*}\right) E_{t}\left(S_{t+1} \frac{U^{\prime}\left(C_{t+1}\right)}{P_{t+1}}\right)=S_{t} \frac{U^{\prime}\left(C_{t}\right)}{P_{t}} .
$$

Equations (1) and (2) imply:

$$
\left(1+i_{t}\right) E_{t}\left(\frac{U^{\prime}\left(C_{t+1}\right)}{P_{t+1}}\right)=\left(1+i_{t}^{*}\right) E_{t}\left(\frac{S_{t+1}}{S_{t}} \frac{U^{\prime}\left(C_{t+1}\right)}{P_{t+1}}\right) .
$$

This equation ensures that the consumer is indifferent on the margin between domestic and foreign bonds. In a perfect foresight framework, it reduces to:

$$
\left(1+i_{t}\right)=\left(1+i_{t}^{*}\right) \frac{S_{t+1}}{S_{t}}
$$

the familiar uncovered interest parity condition (UIP).

Let us focus temporarily on equation (4). Setting $i_{t}=i_{t}^{*}$ at all dates $t$ implies $S_{t+1}=S_{t}$ in all periods in which UIP holds. For this reason, one may think that the interest rate rule $i_{t}=i_{t}^{*}$ is consistent with a fixed exchange rate regime. But the uncovered interest parity condition is violated ex post in all periods in which unexpected shocks happen. In these circumstances, $i_{t}=i_{t}^{*}$ will ensure stability of expected depreciation, yet an instantaneous movement of the level of the exchange rate will be observed at the time of the shock. In a perfect foresight setting, $i_{t}=i_{t}^{*}$ fails to yield stability of the exchange rate.

\footnotetext{
${ }^{3}$ The assumption of additive separability simplifies the notation in what follows. It does not affect the nature of our results in any significant way.
} 
The same problem exists in a rational expectation framework. If the domestic interest rate is pegged to the foreign rate, condition (3) boils down to

$$
E_{t}\left[\frac{U^{\prime}\left(C_{t+1}\right)}{P_{t+1}}\left(1-\frac{S_{t+1}}{S_{t}}\right)\right]=0 .
$$

$S_{t+1}=S_{t}$ in all periods solves this equation. ${ }^{4}$ However, equation (5) must hold at all dates only in expected value. Unanticipated deviations of the exchange rate from the constant path-generated by unexpected disturbances to the economy-will still be consistent with the arbitrage condition and rule $i_{t}=i_{t}^{*}$.

Failure to stabilize the level of the exchange rate is not the only problem of interest rate pegging, though. Even if setting $i_{t}=i_{t}^{*}$ were sufficient to implement a fixed exchange rate equilibrium, a fundamental problem of determinacy of the latter would still exist: $i_{t}=i_{t}^{*}$ would produce an infinite number of fixed exchange rate equilibria. To see this, suppose the domestic central bank targets the level of the exchange rate $S^{*} . S_{t}=S^{*}$ at all dates $t$ is a solution to equation (5). But so is $S_{t}=S^{*}+\mu$ at all dates $t$, where $\mu$ can assume any value. There are infinitely many possible fixed exchange rate equilibria under rational expectations.

We can relate the indeterminacy of the exchange rate under interest rate pegging to Kareken and Wallace's (1981) indeterminacy result. ${ }^{5}$ There, agents in the domestic and the foreign economy are free to hold the currencies of both countries and are indifferent between the two currencies as long as their rates of return are equal. Purchasing power parity (PPP) holds. Governments print money to finance spending. In equilibrium, absence of unexploited arbitrage opportunities between the two currencies implies that there cannot be anticipated changes in the exchange rate. However, any constant value of the exchange rate $S \in(0, \infty)$ can be an equilibrium, because combining the two governments' budget constraints yields one equation in two variables: the exchange rate and the price level. As under the $i_{t}=i_{t}^{*}$ policy in our example, monetary policy does not pin down the exchange rate in the Kareken-Wallace model once arbitrage opportunities have been removed by equalization of returns.

To summarize: $(i)$ Interest rate pegging fails to deliver a fixed exchange rate. For example, there are always equilibria in which the exchange rate is not fixed and jumps unexpectedly at each point in time. (ii) In addition, there exists a multiplicity of fixed exchange rate equilibria. Results $(i)$ and $(i i)$ together yield a simple "second generation" explanation of currency crises that focuses on sudden "sunspot"-driven shifts from one path of the exchange rate to another. ${ }^{6}$ These shifts would be entirely consistent with the rule followed by the central bank and with agents' rational optimizing behavior. Given the link between asset prices and the real economy through the Euler equations (1) and (2), indeterminacy

\footnotetext{
${ }^{4}$ The marginal utility of consumption and the price level are always positive.

${ }^{5}$ See also Ljungqvist and Sargent (2000, pp. 385-386).

6 "First generation" explanations focus on fundamental determinants of currency crises (Krugman, 1979). Obstfeld (1994) is an example of "second generation" model.
} 
and instability of the exchange rate would translate into indeterminacy and instability of the real economy. ${ }^{7}$ Results $(i)$ and $(i i)$ imply that analyses of the properties of fixed exchange rates should not focus on interest rate pegging as the operational rule that implements the regime. Taking $i_{t}=i_{t}^{*}$ as the rule consistent with a fixed exchange rate fails to consider points $(i)$ and $(i i)$.

Having established this, we turn to the design of interest rules for exchange rate stability (and determinacy).

\section{Designing Interest Rate Rules for Exchange Rate Stability}

Suppose the home central bank can credibly commit to the rule

$$
1+i_{t}=\left(1+i_{t}^{*}\right) \phi\left(\frac{S_{t}}{S^{*}}\right)
$$

in which $\phi($.$) is a function with characteristics that we will discuss later.$

Two features of rule (6) are worth immediate remarks. First, rule (6) is known at time $t$. It does not involve uncertainty on the state of nature at time $t+1$. Second, the zero bound on the nominal interest rate implies a lower bound on the function $\phi($.$) :$

$$
\phi\left(\frac{S_{t}}{S^{*}}\right) \geq \frac{1}{1+i_{t}^{*}} \geq 0,
$$

where the second inequality holds strictly as long as $i_{t}^{*}$ is finite.

Substituting rule (6) into the arbitrage condition (3), we obtain:

$$
E_{t}\left\{\frac{U^{\prime}\left(C_{t+1}\right)}{P_{t+1}}\left[S_{t+1}-S_{t} \phi\left(\frac{S_{t}}{S^{*}}\right)\right]\right\}=0
$$

which can be rewritten as:

$$
\sum_{z_{t+1} \in Z_{t+1}} \pi\left(z_{t+1}\right)\left\{\frac{U^{\prime}\left(C_{t+1}\left(z_{t+1}\right)\right)}{P_{t+1}\left(z_{t+1}\right)}\left[S_{t+1}\left(z_{t+1}\right)-S_{t} \phi\left(\frac{S_{t}}{S^{*}}\right)\right]\right\}=0,
$$

where $Z_{t+1}$ is the set of all the finite number of states of nature at time $t+1$ and $z_{t+1}$ is a particular state at date $t+1$.

We require that the function $\phi($.$) satisfies certain properties in addition to$ $\phi($.$) being a function and the lower bound (7):$

- $\phi(1)=1$;

\footnotetext{
${ }^{7}$ We are implicitly assuming that the economy is characterized by some degree of nominal rigidity. In a model with (separable) money in the utility function, indeterminacy of the exchange rate would cause indeterminacy of real balances under flexible prices if it caused indeterminacy of foreign inflation. This, of course, depends also on the foreign policy rule. Domestic real balances will be determinate, even if the exchange rate is not, if the foreign policy rules ensures a unique path for $i_{t}^{*}$.
} 
- $\phi($.$) continuous;$

- $\phi($.$) monotone non-decreasing;$

- $\phi($.$) differentiable;$

- $\phi($.$) strictly increasing in a neighborhood of S_{t}=S^{*}$.

First, we show that given the above properties, there exists only one possible path in which the exchange rate remains always fixed. Along this path, $S_{t}=S^{*}$ $\forall t$. Second, we show that if $S_{t} \neq S^{*}$ at any time $t$, there exists a positive probability that the exchange rate will go either to infinite or to zero as time tends to infinite.

As for the first step, observe that, given the properties of the function $\phi($. and the fact that $\frac{U^{\prime}\left(C_{t+1}\left(z_{t+1}\right)\right)}{P_{t+1}\left(z_{t+1}\right)}$ is positive, a necessary and sufficient condition for equation (8) to be satisfied under a fixed exchange rate is that the term in square brackets be zero in all states $z_{t+1}$ at time $t+1$, i.e.,

$$
S_{t+1}\left(z_{t+1}\right)=S_{t} \phi\left(\frac{S_{t}}{S^{*}}\right)
$$

in all states $z_{t+1}$. This is a set of non-linear difference equations-one per each state of nature at time $t+1$-that can be solved graphically, as we do in Figure 1. ( $S_{t}$ is on the $x$-axis, $S_{t+1}\left(z_{t+1}\right)$ is on the $y$-axis. Of course, there will be a graph for each state of nature.)

$S_{t}=0$ at all dates $t$ is always a solution to equation (9). However, as long as there is positive demand and finite supply of the foreign currency in the world economy, this solution will be ruled out by agents' optimal behavior. Demand for money can be motivated in several ways in a microfounded model, including the familiar money-in-the-utility-function approach or a cash-in-advance constraint. Money demand will be strictly positive if the opportunity cost of holding currency is finite. A positive demand for the foreign currency, combined with the foreign central bank's commitment to a finite quantity of currency, will ensure that its value in terms of the domestic one is strictly positive, i.e., $S_{t}>0$.

$S_{t}=S^{*}$ at all dates $t$ is another solution to equation (9) under the assumption that $\phi(1)=1$, which implies $S_{t}=S^{*}$ at all dates and in all states of nature. Given the restrictions on the function $\phi($.$) , there is a unique rational$ expectations, fixed exchange rate solution to equation (9).

Now consider the second step. We show that there are other possible paths for the exchange rate, but if $S_{t} \neq S^{*}$ at any time $t$, there exists a positive probability that the exchange rate will go either to infinite or to zero as time tends to infinite.

Suppose that $S_{t}>S^{*}$. Equation (8) implies that either all the terms in square brackets are zeros or some of the terms are positive and others are negative. In the first case, following Figure 1, the exchange rate at time $t+1$, in all states of nature, will be such that $S_{t+1}>S_{t}$, given the properties on $\phi($.$) .$ In the second case, if some square-bracket terms are negative, it must be the 
case that at least one of the terms is positive, in order for the equality in (8) to be satisfied. This implies that there will be at least a state $z_{t+1}^{\prime}$ in which $S_{t+1}\left(z_{t+1}^{\prime}\right)>S_{t} \phi\left(\frac{S_{t}}{S^{*}}\right)>S_{t}$. Thus, under both situations there exists a state $z_{t+1}^{\prime}$ with positive probability of occurrence in which $S_{t+1}\left(z_{t+1}^{\prime}\right)>S_{t}>S^{*}$. We can then repeat the same argument at time $t+2$, and find a state $z_{t+2}^{\prime}$ in which $S_{t+2}\left(z_{t+2}^{\prime}\right)>S_{t+1}\left(z_{t+1}^{\prime}\right)>S_{t}>S^{*}$. By iterating the argument, we obtain that, if $S_{t}>S^{*}$, there exists a path with positive probability in which the exchange rate goes to infinite as time tends to infinite. The argument works also for the case $S_{t}<S^{*}$. In this case, there is a positive probability that the exchange rate goes to zero as time tends to infinite. ${ }^{8}$

To summarize, we have shown that either the exchange rate is fixed or there is a positive probability that the exchange rate will explode or implode in an infinite time.

How can we rule out these explosive equilibria and determine a unique rational expectations equilibrium with a fixed exchange rate under rule (6)?

We can eliminate the explosive solutions by assuming that authorities are committed to "drastic" policy actions if the exchange rate settles on an explosive path. An example of such commitment is the assumption that each policymaker can back its nominal liabilities with a fraction, even small, of some assets (such as gold) or with goods, in the case the currency becomes too devalued. This is the solution proposed by Obstfeld and Rogoff (1983). To understand the mechanism, assume that foreign monetary policy is such that the foreign price level $P^{*}$ is well-behaved and follows a path that is not exploding to infinite or imploding to zero. ${ }^{9}$ Suppose further that changes in the exchange rate are eventually passed through to prices in the economy, so that PPP holds in the long run: $P_{T}=S_{T} P_{T}^{*}$ for $T$ sufficiently large. For any given $P_{T}^{*}>0, S_{T} \rightarrow \infty$ as $T \rightarrow \infty$ implies $P_{T} \rightarrow \infty$. As a consequence, the real value of domestic currency $\left(\frac{1}{P_{T}}\right)$ is falling to zero as $T$ goes to infinite. But now suppose that home policymakers-government and the central bank-are committed to redeeming their nominal liabilities for goods at a rate $\frac{1}{P^{\prime}}<\frac{1}{S^{*} P^{*}}$. The authorities are backing their nominal liabilities with real consumption at a value that is below their real value in the fixed exchange rate equilibrium. (The implicit assumption is that the resources for this are generated by tax revenues when needed.) This fractional backing imposes a strictly positive lower bound on the real value of nominal liabilities, including money, and causes the explosive equilibrium in which $S_{T} \rightarrow \infty$ to unravel, thus ruling it out. The assumption that the foreign price level is well-behaved (possibly by virtue of the credible commitment to similarly drastic policy actions abroad) rules out the equilibrium in which $S_{T} \rightarrow 0$ and $P_{T}^{*} \rightarrow \infty$ as $T \rightarrow \infty$ for any strictly positive, finite $P_{T}$.

Credible commitment to rule (6) (and fractional backing), combined with the proper choice of the function $\phi($.$) and agents' rational optimizing behavior,$

\footnotetext{
${ }^{8}$ The fact that the exchange rate goes to zero only asymptotically implies that this case is not ruled out by a requirement of positive money demand and finite supply.

${ }^{9}$ This is not a particularly strong assumption, as importing monetary discipline from the leader country is usually the rationale for an exchange rate peg. (More on the role of the leader country below.)
} 
yields exchange rate stability and determinacy. Because $S_{t}=S^{*}$ in the unique equilibrium of the economy, the rule yields $i_{t}=i_{t}^{*}$ endogenously at each date $t$ as a feature of the rational expectation equilibrium. In other words, given credible commitment to-say-raise the domestic (gross) interest rate above the foreign one by the amount dictated by the function $\phi($.$) each time S_{t}$ tends to move above $S^{*}$, the central bank will never actually need to exercise its threat in equilibrium, and interest rate equalization will follow.

Since the requirements that the function $\phi($.$) should satisfy in order to be$ consistent with a fixed exchange rate are weak, it follows that an infinite number of rules are consistent with the implementation of a fixed exchange rate regime by the home central bank. As all these rules reduce to $i_{t}=i_{t}^{*}$ in equilibrium, all rules consistent with the exchange rate being fixed at $S^{*}$ yield the same level of welfare in a determinate economy. ${ }^{10}$

What happens if the home central bank's commitment to a rule of the form (6) satisfying the requirements above is not perfectly credible?

Suppose that there exists a finite $S^{* *}>S^{*}$ such that $\phi\left(\frac{S^{* *}}{S^{*}}\right)=1$, because it is perceived that the central bank will not actually raise the interest rate if the exchange rate rises well above a certain threshold. In this case, there exists another equilibrium that can be associated with an infinite number of stochastic equilibrium trajectories converging to it (see Figure 2). ${ }^{11}$ A sudden change in expectations away from the solution $S^{*}$-possibly triggered by a change in the color of sunspots-will cause the exchange rate to move from $S^{*}$ to $S^{* *}$ and yield a "second generation" exchange rate crisis. ${ }^{12}$

The relatively weak requirements we impose on the function $\phi($.$) are indeed$ designed to ensure that credibility of the commitment to the rule that determines a unique fixed exchange rate equilibrium is as strong as possible. For example, requiring $\phi($.$) to be strictly convex would have been consistent with the purpose$ of determining a unique equilibrium-along with other conditions. However, a strictly convex function $\phi($.$) would force the home central bank to raise its$ interest rate at a very steep pace in case of deviations of the exchange rate above $S^{*}$. This may indeed weaken the commitment to the rule and set the scope for situations of the type we just discussed.

We conclude this section by observing that we can relate the indeterminacy result under interest rate pegging and our proposed solution to Sargent and Wallace's (1975) criticism of interest rate targeting and the discussion in Woodford (2003, Ch. 2). The rule $i_{t}=i_{t}^{*}$ specifies the path of the domestic interest rate in terms of a path (that of the foreign interest rate) that is "exogenous,"

\footnotetext{
${ }^{10} \mathrm{An}$ alternative to the rule we consider would be a rule based on the money demand equation and relying on the link between the domestic CPI and the exchange rate provided by purchasing power parity (if this holds). Also this rule would yield $i_{t}=i_{t}^{*}$ endogenously in the fixed exchange rate equilibrium, and it would generate the same level of welfare as the rule proposed in the text. The advantage of the latter is that it does not require knowledge of the money demand function.

${ }^{11}$ The specific trajectory will depend on the realizations of the states of nature during the transition. In Figure 2, the home interest rate is lower than $i_{t}^{*}$ to the right of $S^{* *}$. Of course, other cases are possible.

12 The experience of Sweden in 1992 is a good example.
} 
in the sense that it does not make the domestic interest rate directly a function of the endogenous variable that the rule would like to pin down-the exchange rate. (If the home economy is not a small open economy, $i_{t}^{*}$ may be affected by domestic economic developments depending on the design of foreign policy. Yet, the key observation is that the rule $i_{t}=i_{t}^{*}$ does not specify the path of $i_{t}$ as a function of $S_{t}$ or of other variables that are related to $S_{t}$ in a way that would pin it down.) As such, $i_{t}=i_{t}^{*}$ is an example of the interest rate targeting policies criticized by Sargent and Wallace for causing indeterminacy. Making the path of $i_{t}$ a function of $S_{t}$ in the proper way yields exchange-rate determinacy (and generates $i_{t}=i_{t}^{*}$ as an endogenous outcome), much as Woodford's Wicksellian reaction of the interest rate to the price level in a closed economy yields price-level determinacy and a response to Sargent and Wallace's argument.

\section{World Determinacy: The Role of the Leader Country}

So far, we have focused on interest setting by the follower country in the exchange-rate arrangement. A properly designed rule for the home economy yields a determinate equilibrium with a fixed exchange rate. However, this is not sufficient to ensure determinacy of other domestic (or foreign) variables. For example, if purchasing power parity holds, a fixed exchange rate implies that the domestic price level is tied to the foreign one. If the latter is subject to indeterminacy because foreign monetary policy does not ensure its determinacy, the domestic price level will be indeterminate too. Similarly, domestic real variables may be subject to indeterminacy caused by monetary policymaking in the leader country. The rule followed by this country is crucial to ensure determinacy of the world economy. Because home imports foreign monetary policy in equilibrium, interest setting in the foreign country determines the characteristics of the world economy equilibrium.

We do not want to discuss the issue in detail here, rather we focus on a simple example to make our point. Suppose the home economy is following rule (6), with the proper choice of $\phi($.$) . The foreign economy follows a rule of the$ type:

$$
1+i_{t}^{*}=\phi^{*}\left(Y_{t}^{*}, \pi_{t}^{*}\right),
$$

where $Y_{t}^{*}$ and $\pi_{t}^{*}$ are foreign GDP and CPI inflation, respectively.

Rule (10) is a generalized Taylor-type rule for interest setting. The choice of the function $\phi^{*}(.,$.$) determines its characteristics. If \phi^{*}(.,$.$) is not chosen$ appropriately, instability and indeterminacy of the world economy may result. ${ }^{13}$

A multiplicity of choices of $\phi^{*}(.,$.$) will ensure stability and determinacy.$ The specific function chosen in this subset will set the characteristics of the determinate equilibrium of the world economy. In particular, different choices of $\phi^{*}(.,$.$) will yield different welfare levels in the foreign and home economies.$

\footnotetext{
${ }^{13}$ The Sargent-Wallace-Woodford debate over indeterminacy and interest rate setting applies again here.
} 
The foreign rule determines the nature of the fixed exchange rate regime, so that we may say there is a multiplicity of fixed exchange rate regimes depending on the rule followed by the leader, each of them characterized by a different level of welfare. Each regime can be then implemented by a set of welfare-neutral interest setting rules in the follower country.

\section{Conclusions}

Pegging the domestic interest rate to that of a foreign, leader country does not yield a fixed exchange rate. It results in instability and indeterminacy. Interest rate setting to achieve a determinate fixed exchange rate is a subtle issue. We have proposed rules for the follower country in a fixed exchange rate regime that ensure determinacy of the fixed exchange rate equilibrium in a rational expectations setting under relatively weak conditions. A multiplicity of welfare-neutral rules will do. The rule of the leader country is important to have determinacy of the world equilibrium and will set the other macroeconomic features of the fixed exchange rate regime.

\section{References}

[1] Carlstrom, C. T., and T. S. Fuerst (2001): "Timing and Real Indeterminacy in Monetary Models," Journal of Monetary Economics 47, 285-298.

[2] Kareken, J., and N. Wallace (1981): "On the Indeterminacy of Equilibrium Exchange Rates," Quarterly Journal of Economics 96, 107-122.

[3] Krugman, P., (1979): "A model of balance of payments crises," Journal of Money, Credit, and Banking 11, 311-325.

[4] Ljungqvist, L., and T. J. Sargent (2000): Recursive Macroeconomic Theory, Cambridge: MIT Press.

[5] Obstfeld, M. (1994): "The Logic of Currency Crises," Cahiers Economiques et Monétaires (Banque de France) 43.

[6] Obstfeld, M., and K. Rogoff (1983): "Speculative Hyperinflations in Maximizing Models: Can We Rule Them Out?" Journal of Political Economy 91, 675-687.

[7] Sargent, T. J., and N. Wallace (1975): "Rational' Expectations, the Optimal Monetary Instrument, and the Optimal Money Supply Rule," Journal of Political Economy 83, 241-254.

[8] Woodford, M. (2003): Interest and Prices: Foundations of a Theory of Monetary Policy, Princeton: Princeton University Press. 


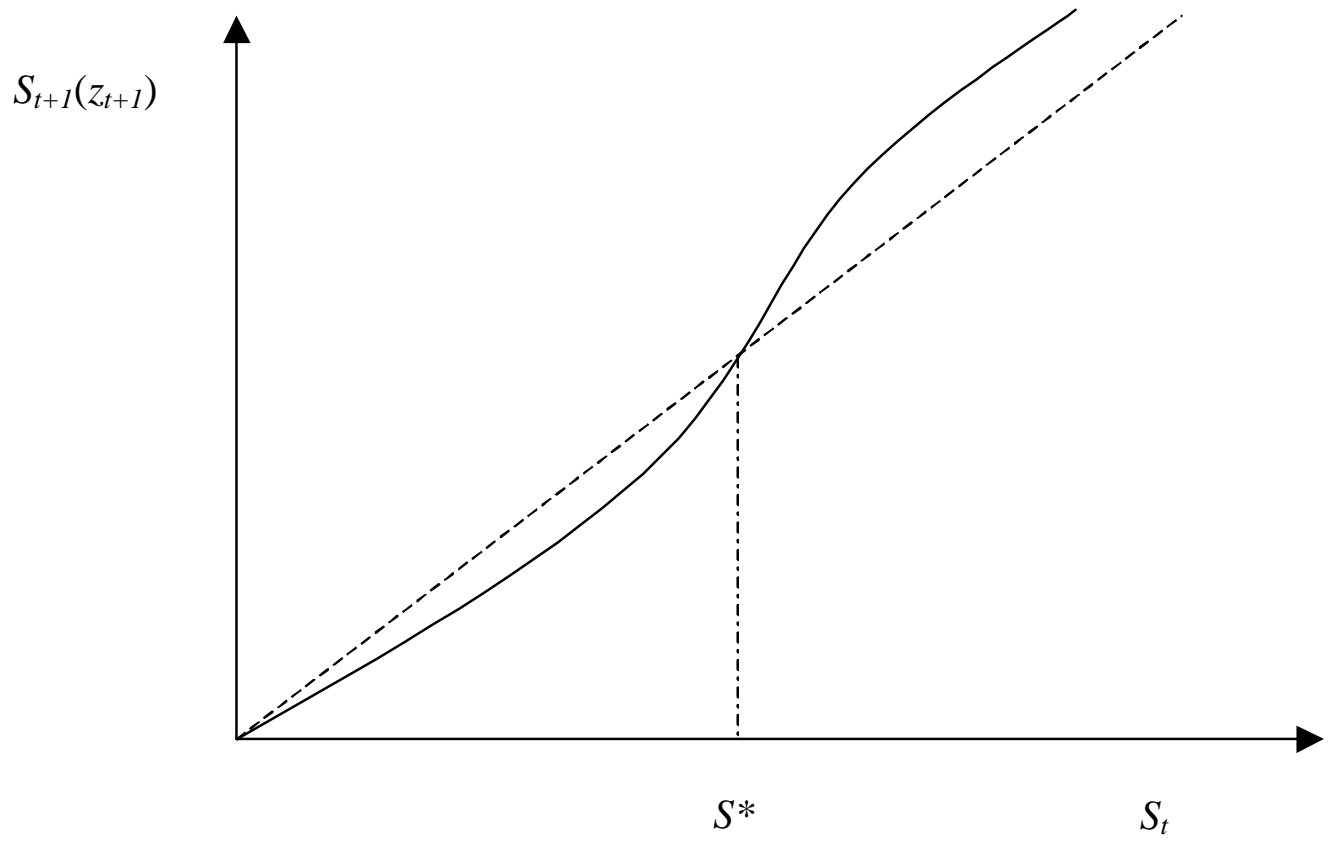

Figure 1

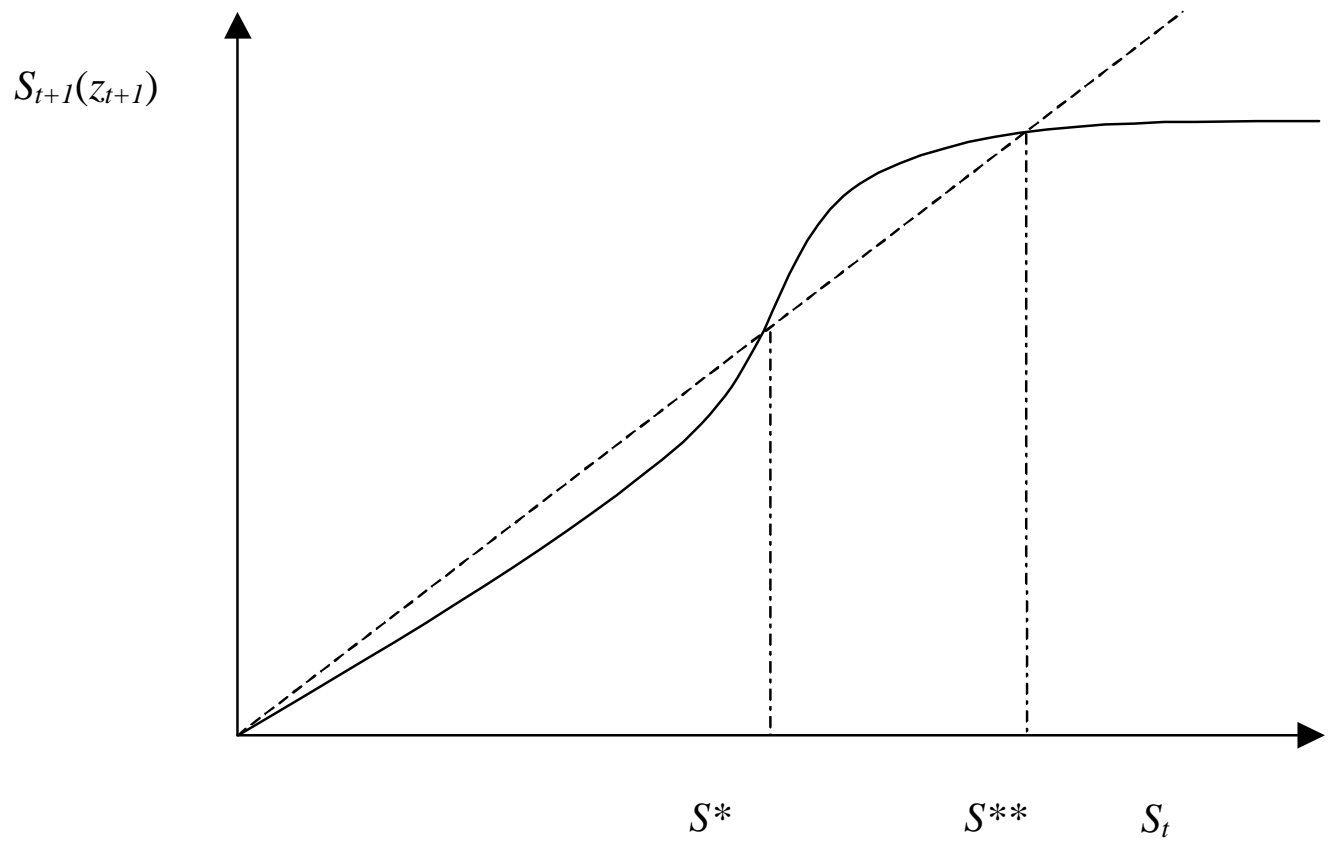

Figure 2 